\title{
The Phenolic Quality of Red Grapes at Delivery: Objective Evaluation with Colour Measurements
}

\author{
E. Celotti ${ }^{1 *}$ and G. Carcereri De Prati ${ }^{2}$ \\ (1) University of Udine - Department of Food Sciences (Viticulture and Enology Section), via Marangoni, 97, 33100 Udine/Italy \\ (2) Consultant on Viticulture and Enology, via Sottomonte di sopra, 7, 37031 Illasi/Verona/Italy
}

Submitted for publication: September 2004

Accepted for publication: September 2005

Key words: Grapes, quality, polyphenols, colour, colorimetry, anthocyanins

\begin{abstract}
The current research evaluated the possibility of the real time (before crushing) measurement of the phenolic quality index of red grapes to define the true quality of the raw material destined for the production of wine or juice. The measurement procedure involved the use of a spectrometer and the acquisition of a reflectance spectral signal via optical fibres immersed directly in the sample to be analysed. The measurements were done on the same juice (grape must) used for refractometry analysis of the sugars. It was established that it was possible to objectively classify the red grape cultivars tested on the basis of their anthocyanin and total polyphenol content. The experiments done in the winery and laboratory demonstrate a positive correlation between the colour of the must sampled from the grape at delivery and the total polyphenols in that grape. The colorimetric parameter can be acquired instantly and the data used in real time to improve the management of the winemaking process and to pay for the grapes on the basis of their phenolic quality.
\end{abstract}

The evaluation of grape quality in the enology sector is still generally performed by analysing only the sugar content of a sample of juice obtained from the batch of grapes at the time of delivery. Only a few companies also evaluate the titratable acidity of the same juice to determine a further parameter for the commodity classification of the grapes.

However, it is now well known that it is not only sugars and acids that determine grape quality, but also other components, in particular polyphenol and aromatic compounds (GonzalesSanJose \& Diez, 1992; Dupuch, 1993; Glories \& Augustin, 1993; Calò et al., 1994; Ruiz Hernandez, 1996; Barcelo, 1997; Robin et al., 1997; Venencie et al., 1997; Celotti et al., 1999; Celotti \& Carcereri, 2000). Notwithstanding their critical importance, these parameters are never quantified in the grapes at delivery time, when the series of processes begins for the transformation into juice or wine.

The introduction of titratable acidity and $\mathrm{pH}$ as determinants on the effect of delivery of grapes was first considered 15 years ago (Anon, 1988). These analyses are however rather delicate as they involve a destructive analysis and the use of a glass electrode and an alkaline reagent. The minimum requirements are periodic cleaning of the electrode and checking that it is functioning correctly by daily or more frequent calibration.

Acidity is an important parameter for the evaluation of the grapes. In particular it gives useful indications for the winemaking technique (to enable adjustments to be made) and of possible problems concerning the microbiological stability of the wine. However, in terms of relative importance, acidity is certainly less useful than the sugar content.
In contrast, for red grapes the polyphenolic profile is an important element of grape quality, as the principal organoleptic qualities of red wine are derived from it. Sometimes it is more important than the sugars. As a consequence, an evaluation of the phenolic quality of red grapes at delivery to the winery, before crushing, could be extremely useful for optimising the winemaking process and, retrospectively, for the introduction of an additional objective parameter for payment for grape quality (Celotti \& Carcereri, 2000).

The aromatic quality, especially for the aromatic varieties, that is, those in which the grapes have varietal aroma, or their precursors, may also be very useful as a further quality parameter, although at the moment there are no analytical systems capable of evaluating this parameter in real time at grape delivery.

Currently the phenolic potential can be evaluated in the laboratory by using various destructive analyses. These involve the disruption of the skin cells and phenol extraction (McCloskey \& Yengoyan, 1981; Dupuch, 1993; Glories \& Augustin, 1993; Venencie et al., 1997). This approach is however not fast enough, even though it provides very detailed information about the various classes of polyphenols present in the grapes. A much more suitable method is the measuring the phenolic potential of red grapes by using non-destructive analytical methods, such as the direct measurement of colour in the grape juice at grape delivery.

Colorimetry combined with other spectroscopic techniques has been used for a long time, even in the non-food sector, but the applications are mainly laboratory based and refer to colour measurements aimed at defining parameters for an item from which some sort of judgement about the type or quality of item involved

*Corresponding author: E-mail address: emilio.celotti@uniud.it

Acknowledgements: The authors thank the Cantine dei Colli Berici/VI/Italy, Maselli Misure/Parma/Italy, and Messrs. Nicola Macrì, Sabrina Cantoni and Mirko Trevisi for their collaboration. 
can be derived (Chen et al., 1972; Huggart et al., 1976; Wildenradt \& Caputi, 1976; Wrolstadt, 1976, Inkrott \& Gould, 1979; Gould, 1982; Lanza \& Li, 1984; Buslig \& Wagner, 1988; Kyu et al., 1995; Ameny \& Wilson, 1997; Mateo \& Bosch, 1998; Wang et al., 1999). Furthermore, there are on-line industrial applications in which colour measurements are used, for example, to evaluate the flow of different fluids in pipes or the evaluation of any sort of colour variation in a liquid or solid object (Clydesdale, 1973; Setser, 1984; McGuire, 1992; Mabon, 1993).

Some applications exist for evaluating grape quality with the FTIR (fourier, transform infrared), NIR (near infrared), and glucosyl-glucose systems (Lanza \& Li, 1984; Garcia \& Medina, 1997; Gishen \& Dambergs, 1999; Dubernet \& Dubernet, 2000), but these are laboratory applications and are not used on samples of cloudy must at delivery for immediate analysis with the aim of classifying on the basis of phenolic maturity. These references are moreover outside the scope of the present work, which evaluates the spectrum in the VIS range.

Beginning with the supposition that very mature red grapes release much colour simply by being rubbed between fingers, the current research has evaluated the possibility of real time measurements, before crushing, of the phenolic quality of red grapes. This, together with the measurement of the sugar content and acidity, will be used in an attempt to obtain the most appropriate evaluation of the grapes to define their quality.

\section{MATERIALS AND METHODS}

\section{Origin of grapes}

The experiments involved the examination of red grapes delivered to wineries in Italy, Spain and Australia (years 1999, 2000 and 2001). During the laboratory development of the method, stored grapes in climatised cells were used for some of the tests carried out in winter (Corvina and Corvinone). In order to increase the experimental range, samples were collected of various varieties of red grapes representing Central and Northern Italy (Cabernet, Merlot, Raboso, Nebbiolo, Barbera, Lambrusco, Sangiovese, Tempranillo, Aglianico, Shiraz).

\section{Sampling and colour measurement}

The colour measurements were made on the grape juice obtained from whole berries using a fruit juicer, thus simulating the effect of the sampling system of the must from the trailer, used to determine the sugar level. As it is an appliance that is available on the market, the conditions of use were standardised to ensure a constant volume of juice to be analysed under the same working centrifugation conditions in the laboratory. The colour measurements were also carried out on-line on the must. Samples were obtained from the trailer by means of a rotary drilling system. The sampling system was composed of a rotary drill that collects a sample of the entire vertical section of the grape. The action of the sampling system creates a mechanical effect on the skins, which results in the release of some of the polyphenols into the must to be measured. The mechanical action of the sampling system also causes the sample to become turbid, which is necessary for measuring the reflectance. This must sample was also used to evaluate the sugar concentration by refractometry.

For the analysis of the anthocyanins and other phenolic fractions, the grapes were blended and the homogeneous mass was used for the analysis of the anthocyanins by extraction under dif- ferent $\mathrm{pH}$ conditions and evaluation by decolouration with sulphur dioxide (Glories \& Augustin, 1993). The other phenolic fractions were measured directly by absorbance of a suitably diluted sample.

Some batches of grapes of the same variety, but with different colorimetric values, obtained by evaluating the sampled juice, were made into wine. In this case the maceration technology was similar to that normally used by the winery, but the exogenous operations with enzymes and tannins were excluded. After skin maceration, the colour intensity of the wine was evaluated. At least two vinifications were done for each variety using the same vinification technique (time, temperature, etc.) with the aim of obtaining wines that can be compared analytically in terms of the polyphenol compounds.

The wine analyses that were carried out were: total polyphenols by absorbance at $280 \mathrm{~nm}$, anthocyanins by decolouration with sulphur dioxide, intensity of colour as Abs $420 \mathrm{~nm}+$ Abs $520 \mathrm{~nm}$ + Abs $620 \mathrm{~nm}$.

\section{Colour measurements}

The colour measurements were performed with an instrument supplied by GHT (Giotto High Technology, Padova/Italy); the signal transmitted by the optical fibres was processed by means of the TOP Sensor system software supplied by the same company.

The operating principle of the instrument used to determine colour is based on the spectrophotometric analysis of light. The measurements were performed continuously over the entire spectrum of visible wavelength. The measuring setup consisted of a stabilised halogen source and a reflectance probe; in this case, one extremity of the fibre was connected to the halogen source and the other to the spectrometer. Optical fibres were used to illuminate the sample and acquire the reflected light. The illumination was provided by a D65 with an illuminating angle of $0^{\circ}$, the parameters in the experiment were $\mathrm{L}^{*}, \mathrm{a}^{*}$ and $\mathrm{b}^{*}$ according to the CIELAB system (Gil-Munoz et al., 1997). After the colour was measured the degree of redness $\left(a^{*}\right)$ of the analysed sample was extrapolated. The specific intervals of signal integration is the subject of a patent to which the complete procedure is linked for the objective evaluation of phenolic quality at delivery by the analysis of grape juice colour. Evaluation of the colorimetric parameters verified the higher correlation between parameter $a^{*}$ and the polyphenols. In practice there is a direct correlation between redness and total polyphenols and anthocyanins in the grapes.

The degree of redness given by the instrument was subsequently elaborated according to what was scheduled in the patent (Celotti \& Carcereri, 1999) to provide the corresponding definitive scale of phenolic quality of the red grapes (from 90 to 200 and more). After calibration of the instrument (white and black) the fibre was immersed in the sample in an appropriate cell in order to standardise the measurement and avoid interference from environmental light. It is important that the sample to be measured must be turbid in order to most adequately exploit the light reflected by the sample itself. For this reason the system was applied to samples of turbid grape must obtained from the sampling of the contents of trailers, by using the sampling arm.

The cell is made of steel; it contains $400 \mathrm{~mL}$ of must and is protected from the external light to avoid interference. The measure cell was studied with the aim of obtaining a significant redness 
gradient from grape must with a significant gradient of total polyphenols and anthocyanins, evaluated in accordance with traditional laboratory procedures (Glories \& Augustin, 1993). The same cell was used for all the measurements done in the experiment. Measurements were always taken of samples constantly shaken to avoid bits of skin or grape pips being momentarily positioned on the measuring surface of the probe. The agitator is a 2 blade system, with a speed of $200 \mathrm{rpm}$, positioned at the centre of the cell in order to avoid stratification of the solid particles in the must.

The luminous impulse emitted by the source arrived at the extremity of the probe and interacted with the area to analysed. The result of this interaction was then collected by the same probe and transmitted to the spectrometer.

\section{Statistical analyses}

Statistical analysis of the colorimetric data was performed by means of the statistics package Statistica/W - 6.0 (StatSoft Inc.).

\section{RESULTS AND DISCUSSION}

In order to verify the reliability of the parameter measured, some laboratory evaluations were performed to find the optimum position for the optical fibres that, once immersed in the sample, supplied the colorimetric parameters. Table 1 shows that the repeatability of the measurement of must redness under constant mixing conditions is excellent; in fact the highest value of the coefficient of variation as a function of depth was 2.25 , while the repeatability of the measurement of the maximum value was 1.50 . Thus variation of the depth of the probe, in this case immersed up to 6 $\mathrm{cm}$, had no significant effect on the data. In contrast, mixing the sample was very important as this guarantees the homogeneity of the medium to be analysed and prevents the generation of false data caused by, for example, large particles or grape seeds passing through the measuring area at the instant of data acquisition.

In some tests several samples of must were used for direct measurements of redness and anthocyanin concentration in order to demonstrate the existence of correlations between these parameters. In order to obtain a red chromatic scale, increasing volumes of red wine from the Ancellotta cultivar were added to a sample of turbid must. The strongly coloured Ancellotta wine was added in such a way that the different additions would not significantly alter the total volume, therefore small increasing amounts of very concentrated wine were added to a much greater volume; this allowed an anthocyanin gradient to be obtained without altering the $\mathrm{pH}$ of the means. For this first experiment the determination of colour with the spectrometer and optical fibre system involved placing the sample in a non-transparent white glass with the measuring probe immersed in the sample to a depth of about $2 \mathrm{~cm}$ and held on a suitable support, following criteria determined during previous development tests of the measuring cell.

The values obtained for the relationship between the redness and anthocyanins content (Fig. 1) demonstrated a good relationship between the colorimetric parameter and the anthocyanins; in fact, there was always a linear correlation with optimum values for the $r$ Pearson coefficient of the function.

The linearity of the response allowed the "redness" parameter to be used for any anthocyanin concentration present in the juice. Considering that the direct colour measurement occurs in a turbid sample and that, in contrast, the traditional methods for determining anthocyanins involve samples cleared by centrifugation, the values for the anthocyanins should be lower than the direct colour measurements. Thus, in addition to the normal anthocyanin determination in limpid juice, an additional measurement was made of the anthocyanins on the centrifuged lees. For this analysis, the anthocyanins were extracted by suspension of the turbid fluid with hydrochloric acid at $\mathrm{pH}$ 1.0, and then analysed by means of the sulphur dioxide decolouration method. The anthocyanin concentration is therefore the sum of the value in the limpid juice and that in the turbid mixture, once expressed in terms of the juice starting volume. Figure 1 shows that there was a highly significant relationship between the "redness" parameter and the total anthocyanins and, furthermore, this value (R) was higher than that evaluated for only the clear juice. Moreover, also evaluating the anthocyanins contained in the cloudy particles gives a more accurate measurement of the polyphenols that are present in the wine after vinification, which are also present initially in the suspended particles. On the basis of the results obtained from the laboratory experiments, which demonstrated the correlation between the redness and the anthocyanins in a turbid juice (must), winery-based evaluations were made during the 1999-2000 and 2001 grape harvest at the Colli Berici Winery and several other Italian and Spanish wineries.

The colour measurements were performed on the juice samples at the same time as the sugars were evaluated at the refractometry station. Having observed all the batches of red grapes delivered to the winery, it was possible to obtain reference colour scales for the various cultivars. These evaluations took place in

\section{TABLE 1}

Redness values measured in continuously mixed samples, at different depths in the liquid (red grape must) $(\mathrm{d} 0=\mathrm{depth} 0 \mathrm{~cm} ; \mathrm{d} 3=\mathrm{depth}$ $3 \mathrm{~cm}$; $\mathrm{d} 6=$ depth $6 \mathrm{~cm}) ; \mathrm{RSD}=$ relative standard deviation.

\section{MUST REDNESS}

\begin{tabular}{|c|c|c|c|c|c|c|c|c|c|c|}
\hline Replicate of analysis & 1 & 2 & 3 & 4 & 5 & 6 & 7 & 8 & mean & RSD \% \\
\hline redness $(\mathrm{d} 0)$ & 4.60 & 4.53 & 4.75 & 4.70 & 4.62 & 4.66 & 4.71 & 4.66 & 4.65 & 1.50 \\
\hline redness $(\mathrm{d} 3)$ & 4.73 & 4.63 & 4.56 & 4.62 & 4.60 & 4.63 & 4.67 & 4.70 & 4.64 & 1.18 \\
\hline redness (d6) & 4.70 & 4.62 & 4.58 & 4.59 & 4.58 & 4.68 & 4.69 & 4.66 & 4.64 & 1.10 \\
\hline Mean & 4.68 & 4.59 & 4.63 & 4.64 & 4.60 & 4.66 & 4.69 & 4.67 & & \\
\hline RSD \% & 1.46 & 1.20 & 2.25 & 1.23 & 0.43 & 0.54 & 0.43 & 0.49 & & \\
\hline
\end{tabular}




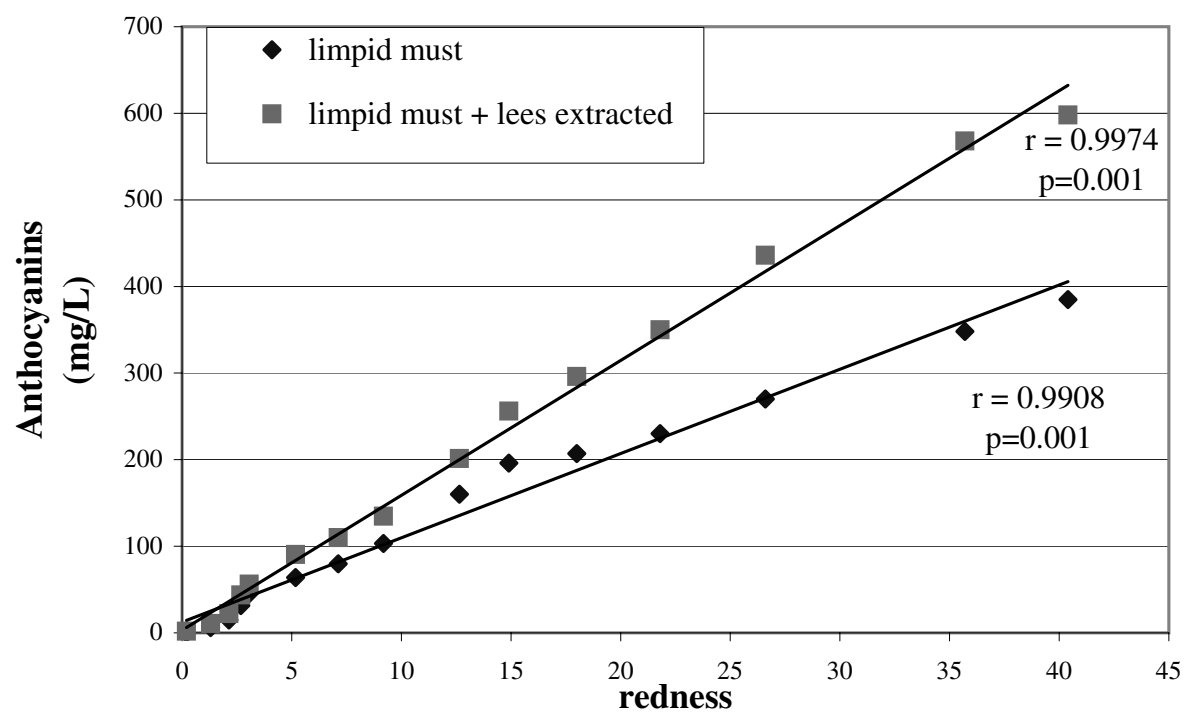

FIGURE 1

Relationship between the redness (from colour analysis) parameter and the anthocyanins in a turbid grape juice (must).

Limpid must $=$ analysis in the limpid must; Limpid must + lees extracted $=$ analysis in the limpid and in the lees after extraction; $r=$ Pearson coefficient

real time on continuously mixed samples, in order to eliminate interference caused by large pieces of skin or grape seeds.

In order to be able to make practical use of the colour measurements made on the juice obtained from the sampling arm, it was necessary to verify that this parameter was correlated with the quantity of anthocyanins and total polyphenols present in the skin of red grapes. Thus, tests were performed on various red grape cultivars. In order to obtain significant data, the evaluations were only made on samples of grapes obtained directly from trailers. The grapes were divided into two equal samples: one was used for the centrifugation to obtain the juice and the other for the analysis of the total anthocyanins. The grapes were chosen on the basis of having apparently different degrees of phenolic maturity, in order to be able to obtain significant redness gradients.

Figures 2, 3 and 4 present several examples of the relationship between must redness and total anthocyanins. There was a good correlation between the redness of the grape juice and the skin anthocyanins, in both the fraction extractable at $\mathrm{pH} 3.2$ and the potential anthocyanins extractable at $\mathrm{pH}$ 1.0. According to Glories \& Augustin (1993) who first described the method, cellular maturity is the parameter linked to the different levels of extraction of the polyphenols from the skin under the different $\mathrm{pH}$ conditions ( $\mathrm{pH} 1.0$ and $\mathrm{pH} 3.2$ ) used. This implies that for a given anthocyanin concentration, cellular maturity does not significantly interfere with the final classification of the grapes obtained from the correlation between the colour measured in the must and the total anthocyanins in the grapes. Another significant point is that the colour measurement is also significantly correlated with the concentration of total polyphenols evaluated by absorption at $280 \mathrm{~nm}$, on both the extract at $\mathrm{pH} 3.2$ and that at $\mathrm{pH}$ 1.0. This is not a cause and effect relationship, but the correlation can surely
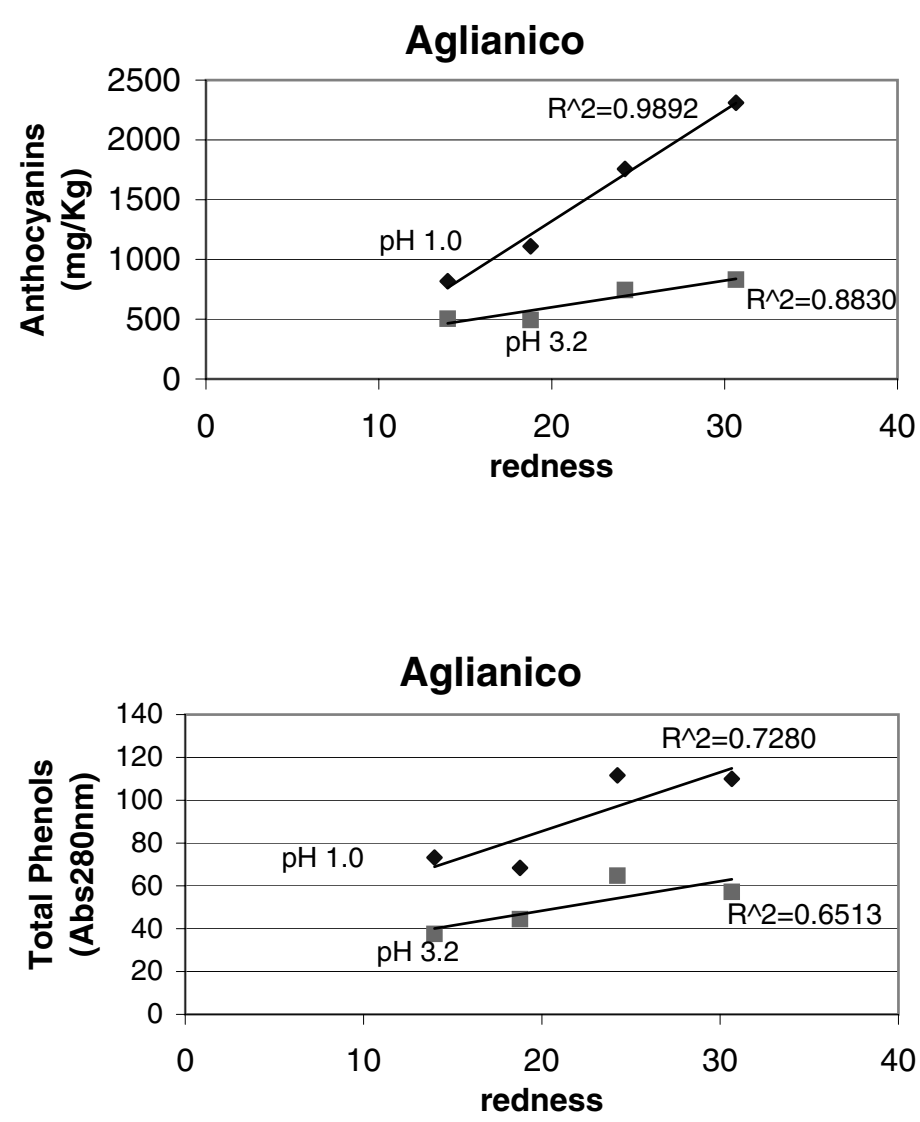

FIGURE 2

Relationship between must redness (from colour analysis) and total anthocyanins and total polyphenols in the Aglianico grapes (from South Italy). 

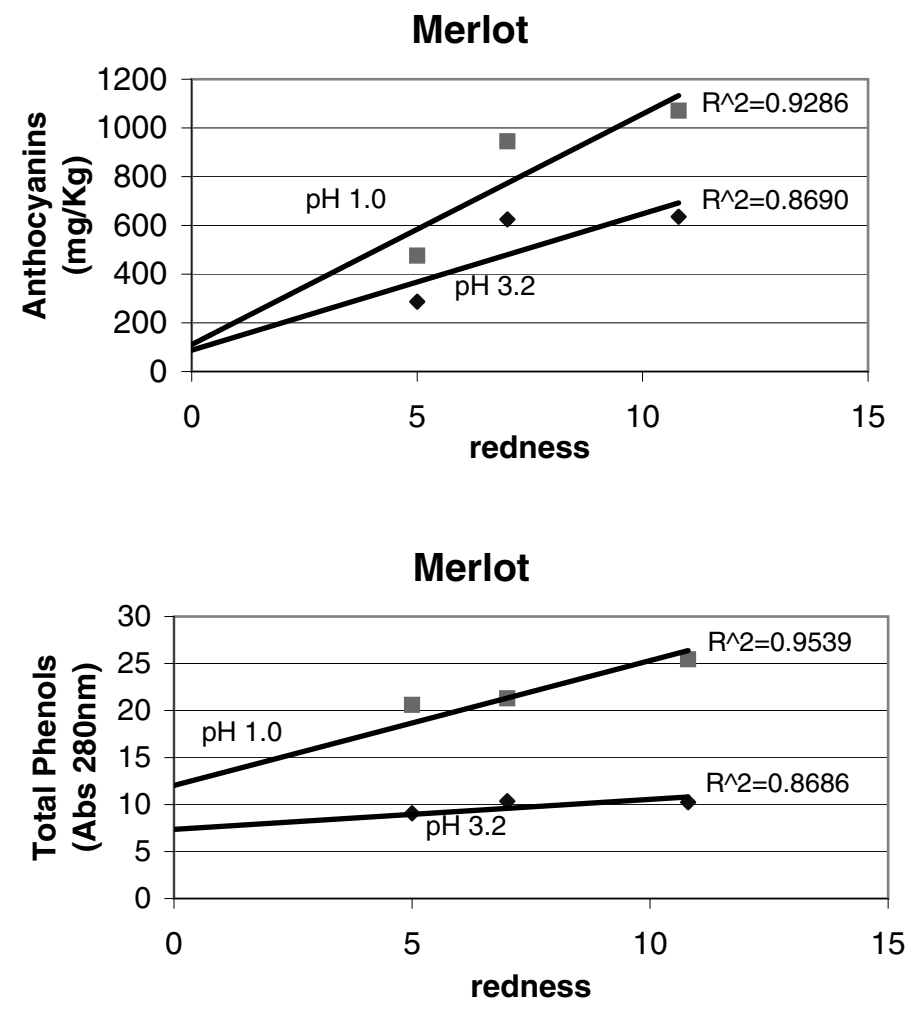

FIGURE 3

Relationship between must redness (from colour analysis) and total anthocyanins and total polyphenols in the Merlot grapes (from North Italy).

be explained by the fact that the polyphenol metabolisms are similar and it is therefore likely that high values of compounds evaluated in VIS correspond to high values of polyphenol compounds evaluated in UV. In effect this is partly a case of evaluations of the same compounds but by different methods.

Variations due to mathematical approximation could have been due to maturity of the grapes, $\mathrm{pH}$ or turbidity. It is, however, clear from the results obtained that it is possible to classify the grapes (at least from 2 to 5 classes) as a function of their anthocyanin and total polyphenol content. Table 2 reports the determination coefficients calculated for several cultivars examined at harvest relative to the function that best approximates the experimental points. The data demonstrate that for the anthocyanins and total polyphenols there is a sufficient correlation level with the redness. This level of correlation between the redness parameter and the polyphenols is sufficient to classify the grapes into from at least two up to n classes. It would, however, be impossible to quantify the polyphenols with this system, but it may be useful to the enologist In fact, the aim of the present work is to provide a tool that can be used by the enologist to discriminate rapidly between different levels of phenolic quality to allow a classification of the grapes on the basis of their overall anthocyanin and polyphenol substances.

The real difference between the traditional system, which involves analysis of the whole grape, is generally carried out in the laboratory. This requires extended analysis. Immediate online evaluation of the juice sampled from the trailer may provide important information, such as classification of the grapes
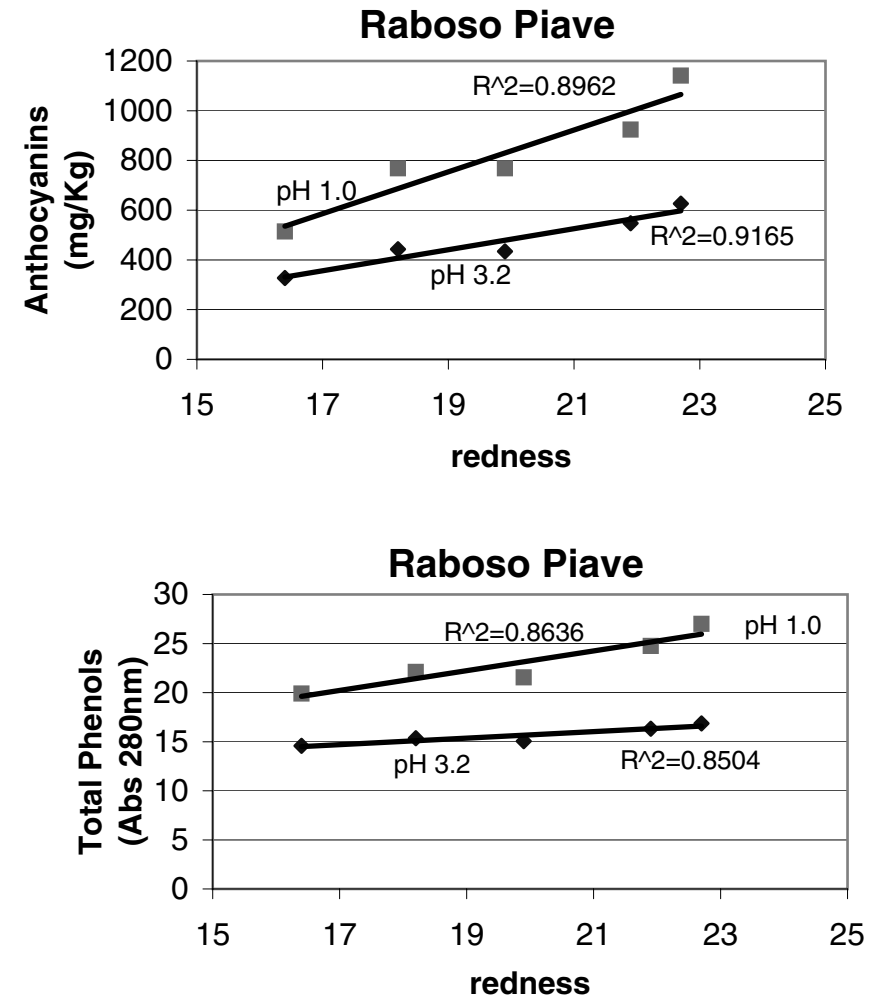

FIGURE 4

Relationship between must redness (from colour analysis) and total anthocyanins and total polyphenols in the Raboso grapes (from North Italy).

TABLE 2.

Coefficients of determination between must redness (from colour analysis) values and anthocyanins and total polyphenols in grapes extracted with solutions at different $\mathrm{pH}$ values. For each cultivar at least $4-5$ samples with different phenolic maturity were selected.

\begin{tabular}{lcccc}
\hline & \multicolumn{2}{c}{ Total anthocyanins } & $\begin{array}{c}\text { Total polyphenols } \\
\text { (Abs 280 nm) }\end{array}$ \\
\hline Cultivar & $\mathbf{r}^{\mathbf{2}}$ & $\mathbf{r}^{\mathbf{2}}$ & $\mathbf{R}^{\mathbf{2}}$ & $\mathbf{R}^{\mathbf{2}}$ \\
& $(\mathbf{p H ~ 3 , 2 )}$ & $(\mathbf{p H ~ 1 , 0 )}$ & $(\mathbf{p H ~ 3 , 2 )}$ & $(\mathbf{p H ~ 1 , 0 )}$ \\
\hline Cabernet (North Italy) & 0.6387 & 0.6479 & 0.6939 & 0.4729 \\
Merlot (North Italy) & 0.8690 & 0.9286 & 0.8686 & 0.9539 \\
Corvinone (North Italy) & 0.6250 & 0.5286 & 0.6807 & 0.6608 \\
Corvina (North Italy) & 0.8608 & 0.8182 & 0.6747 & 0.7636 \\
Raboso Piave (North Italy) & 0.9165 & 0.8962 & 0.8504 & 0.8636 \\
Raboso Veronese & & & & \\
(North Italy) & 0.7084 & 0.7013 & 0.4798 & 0.7035 \\
Nebbiolo (North Italy) & 0.5350 & 0.7595 & 0.9869 & 0.8763 \\
Barbera (North Italy) & 0.8458 & 0.9720 & 0.6913 & 0.9155 \\
Lambrusco (North Italy) & 0.8406 & 0.8095 & 0.7625 & 0.7561 \\
Sangiovese (North Italy) & 0.9994 & 0.9993 & 0.9593 & 0.9271 \\
Tempranillo (Spain) & 0.8967 & 0.9754 & 0,8435 & 0.7964 \\
Cabernet (Australia) & 0.9813 & 0.9832 & 0,9957 & 0.9983 \\
Aglianico (South Italy) & 0.8837 & 0.9891 & 0.6517 & 0.7285 \\
\hline
\end{tabular}


SHIRAZ

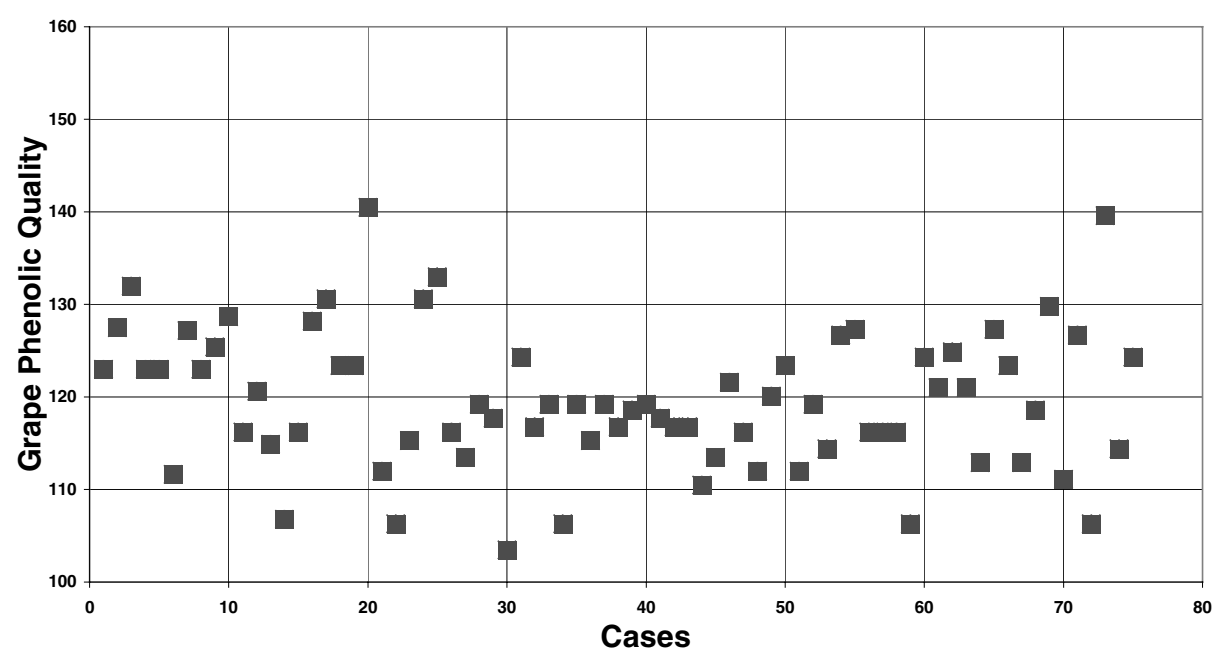

FIGURE 5

Variability of the grape phenolic quality parameter on Shiraz cultivar (from South Italy).

by phenolic quality prior to starting processing operations. It provides an overall index of the polyphenols, while further details can be obtained from the laboratory evaluation on the grape, but which requires long analysis times.

This is an analysis that requires no preparation, as the sample is the same one as that used for determining the sugar level. It has the advantage that a classification of the grapes by classes of phenolic quality is obtained in real time from a colour measurement prior to the processing of the grapes. It is not important in this case to quantify the polyphenols, but merely to classify different batches of grapes, exploiting the concept of difference of maturation by which two batches of grapes with different phenolic maturity also provide two different values of the redness parameter from the analysis of the juice extracted at sampling.

On the one hand, this result is important for the management of the wine-making process and, on the other, it allows the production of a phenolic quality scale at the end of the harvest which could be used for classifying the grapes according to a possible payment system based on phenolic maturity. It would be up to each winery to establish the relative weight and relationship to assign to the anthocyanin quality and the grape price (extreme examples could be grapes for intense red wine and simple red table wine). This additional parameter for the evaluation of grapes could thus be added to those normally used (sugars, acidity) and growing-area criteria for the definition of a more accurate assessment of the quality of grapes.

From the 1999, 2000 and 2001 harvest, a scale of redness elaborated in phenolic quality scale (from colour analysis) for some cultivars is reported as an example. The measured values are sufficiently wide to discriminate different classes of grape phenolic quality (Figs 5 \& 6).

Wine was also made from batches of grapes separated on the basis of the phenolic quality parameter evaluated at the refractometric station on a sample obtained with a sampling drill from
TABLE 3. Relationship between grape phenolic quality (P.Q.) (from colour analysis) and colour intensity (C.I.) of Cabernet wine Abs $420+520+620 \mathrm{~nm}$ (from North Italy).

\begin{tabular}{cc}
\hline & CABERNET SAUVIGNON \\
\hline P.Q. & C.I. of wine \\
\hline 100 & 1.80 \\
102 & 2.60 \\
104 & 3.41 \\
106 & 4.21 \\
108 & 5.02 \\
110 & 5.82 \\
112 & 6.63 \\
114 & 7.43 \\
116 & 8.24 \\
118 & 9.04 \\
120 & 9.85 \\
130 & 13.87 \\
140 & 17.90 \\
150 & 21.92 \\
\hline
\end{tabular}

five sampling points per trailer. This manner of operating is important in order to obtain a sample sufficiently representative of the entire batch of grapes. The data from the wines obtained (Tables $3 \& 4$ ) show that differences in the on-line evaluation of the phenolic quality using the measurement of the colour of the must are always followed by differences in the colour intensity of the wine, obviously using the same vinification technique. These large-scale winemaking experiments represent an in-field verification of the importance a juice colour measurement can have as an additional instrument for the definition of grape quality and an improved management of the winemaking process.

In addition to the enological advantages, this evaluation could become an incentive for different and better management of the 


\section{MERLOT}

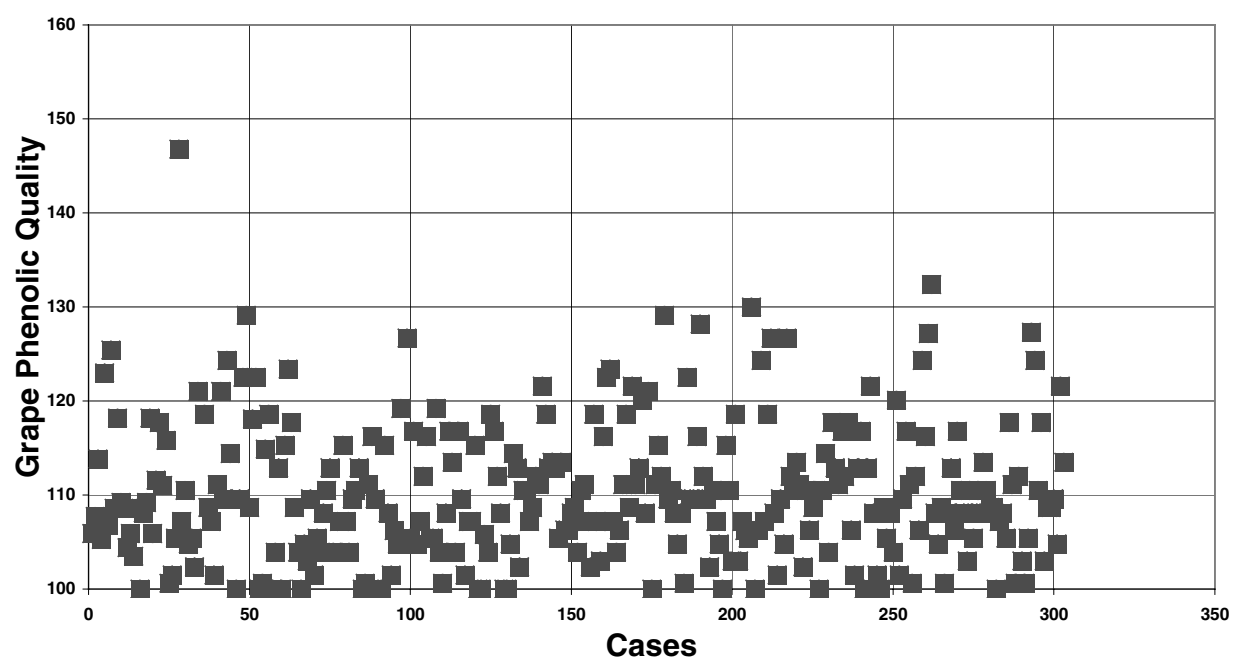

FIGURE 6

Variability of the grape ghenolic quality parameter on Merlot cultivar (from South Italy).

TABLE 4. Relationship between Grape Phenolic Quality (P.Q.) (from colour analysis) and Colour Intensity (C.I.) of Montepulciano wine Abs 420+520+620 nm (from central Italy).

\begin{tabular}{cc}
\hline & MONTEPULCIANO \\
\hline P.Q. & C.I. of wine \\
\hline 120 & 15.17 \\
130 & 16.11 \\
140 & 17.06 \\
150 & 18.01 \\
160 & 18.96 \\
170 & 19.91 \\
180 & 20.86 \\
190 & 21.81 \\
200 & 22.76 \\
\hline
\end{tabular}

vineyard, aimed at obtaining more mature grapes from the phenolic profile, an aspect of fundamental importance for obtaining quality red wines. In fact, it is well known that the quality cannot be exclusively defined on the basis of the sugars, and furthermore the increasingly frequent cases of very sugary grapes with low concentrations of anthocyanins make the evaluation of colour even more interesting..

The absence of significant correlations between the phenolic quality parameter and the sugars at grape harvest, as shown in Table 5, is a confirmation of the validity of the introduction of this measurement. The correlation values were very low and thus it was verified that evaluating only the sugar degree could result in enormous errors when judging the quality of red grapes, often penalising grapes that, although having a high concentration of anthocyanins and total polyphenols, also have a low sugar content.
TABLE 5. Coefficients of determination between phenolic quality values (from colour analysis) and the sugars at harvest (from North Italy).

\begin{tabular}{lcc}
\hline Cultivar/Zone & n (samples) & Coefficient of determination $\left(\mathbf{r}^{\mathbf{2}}\right)$ \\
\hline Cabernet (plain) & 320 & 0.0839 \\
Cabernet (hill) & 347 & 0.2441 \\
Merlot (plain) & 513 & 0.2396 \\
Merlot (hill) & 489 & 0.2909 \\
\hline
\end{tabular}

\section{CONCLUSIONS}

The measurement of colour in fresh grape juice, using the reflectance system, is reliable, repeatable and applicable to the red grape cultivars tested. The parameter of the phenolic quality of the grape, obtained from must "redness", can be obtained instantly and is therefore usable in real time for improving the management of the winemaking process.

It is possible to objectively classify the phenolic quality of red grapes at the time of delivery using a global index related to phenolic compounds. It would be possible to use phenolic quality measurements as an indication of the quality of the gtrapes.

The evaluation of the phenolic potential of red grapes could, in the medium-long term, become an incentive for improving vineyard management with the aim of maximizing the quality level of the grapes produced.

\section{LITERATURE CITED}

Ameny, M.A. \& Wilson, P.W., 1997. Relationship between Hunter colour values and beta-carotene contents in white-fleshed African sweet potatoes. J. Sci. Food and Agric. 73, 301-306.

Anon, 1988. Automatic analysis unit for determination of the acidity of grape musts. Tecnologie Alimentari 11, 41-42. 
Barcelo, J.M., 1997. La gestion de la maturation: le premier acte œnologique. Incidence sur les profils de vins de Syrah dans les Côtes du Rhône. Rev. Fr. CF. $165,24-26$.

Buslig, B.S. \& Wagner, C.J., 1988. Measurement of orange juice colour with the hunterlab LabScan reflectance spectrocolourimeter. Proc. of the Florida State Horticultural Society 101, pp. 147-150.

Calò, A., Giorgessi, F., Pezza, L., Gianotti, S. \& Di-Stefano, R., 1994. Analysis of the variation of some compounds accumulated in grapes according to the pruning system and position of the bud on vine fruit canes (Vitis sp.). Rivista di Viticoltura e di Enologia 47 (4), 3-22.

Celotti, E. \& Carcereri, G., 1999. Procedimento per la valutazione della qualità delle uve rosse alla consegna in cantina e valutazione del succo in diversi momenti fino al caricamento dei serbatoi. Italian Patent UD 99 A 000086, 28/04/99, Università degli Studi di Udine, International Patent, PCT/IB00/00514, WO/00/66986, 25/04/2000, USA patent

Celotti, E. \& Carcereri, G., 2000. Studio della maturità fenolica delle uve rosse per valorizzare l'area viticola dei Colli Berici. L'Enotecnico 36, 79-84.

Celotti, E., Peterlunger, E., Battistutta, F. \& Zironi, R., 1999. Phenolic and aromatic maturity as instruments for evaluating the training system: the case of Sauvignon in Friuli. Proc. $11^{\text {th }}$ Symposium GESCO, Sicilia 6-12 Giugno, pp. 568576.

Chen, C.Y., Skarsaune, S.K. \& Watson, C.A., 1972. Relation of kernel colour to wheat class and grade. Cereal Sci. Today 17, 340-343 (1972).

Clydesdale, F.M., 1973. Colour and haze measurement of beer. Brewers' Digest 48, 46-72.

Dubernet, M. \& Dubernet, M., 2000. Utilisation de l'analyse infrarouge à transformée de Fourier pour l'analyse œnologique de routine. Rev. Fr. E181, 10-15.

Dupuch, V., 1993. Appréciation de la matière phénolique des vins rouges: application à la détermination de la date de récolte. Proc. Colloque "Journée technique du CIVB" 21 Janvier 1993, Bordeaux, pp. 62-69.

Garcia, J.C.M. \& Medina, B., 1997. Application of multivariate calibration to the simultaneous routine determination of ethanol, glycerol, fructose, glucose and total residual sugars in botrytized-grape sweet wines by means of near-infrared reflectance spectroscopy. Fresenius' J. of Anal. Chem. 357, 86-91.

Gil-Munoz, R., Gomez-Plaza, E., Martinez, A. \& Lopez Roca J.M., 1997. Evolution of the CIELAB and other spectrophotometric parameters during wine fermentation. Influence of some pre and post fermentative factors. Food Res. Int. 30, 699-705.

Gishen, M. \& Dambergs, B., 1999. Some preliminary trials in the application of scanning near-infrared spectroscopy (NIRS) for determining the compositional quality of grapes, wine and spirits. Australian Grapegrower \& Winemaker 414a: 43-45-47.

Glories, Y. \& Augustin, M., 1993. Maturité phénolique du raisin, conséquences technologiques: application aux millésimes 1991 et 1992. Proc. Colloque "Journée technique du CIVB" 21 Janvier 1993, Bordeaux, pp. 56-61.

Gonzalez-SanJose, M.L. \& Diez, C., 1992. Relationship between anthocyanins and sugars during the ripening of grape berries. Food Chem. 43, 193-197.

Gould, W.A., 1982. Raw tomato colour evaluation. Research Circular, Ohio Agric. R \& D Center 271, 18-20.

Huggart, R.L., Eagerman, B.A. \& Buslig, B.S., 1976. Determining orange juice colour number with the Agtron M-500-A colourimeter. Food Prod. Develop. 10, 97-100.

Inkrott, D. \& Gould, W.A., 1979. Prediction of finished product juice colour from raw product tomato colour. Research Circular, Ohio Agric. R \& D Center 250, 10 13

Kyu, H.C., Gwi, H.L., Han,Y.J. \& Bunn, J.M., 1995. Tomato maturity evaluation using colour image analysis. Transactions of the ASAE 38, 171-176.

Lanza, E. \& Li, B.W., 1984. Application for near-infrared spectroscopy for predicting the sugar content of fruit juices. J. Food Sci. 49, 995-998.

Mabon, T.J., 1993. Colour measurement of food. Cereal Foods World 38, 21-25.

Mateo, R. \& Bosch, R.F., 1998. Classification of Spanish unifloral honeys by discriminant analysis of electrical conductivity, colour, water content, sugars, and pH. J. Agric. Food Chem. 46, 393-400.

McCloskey, L.P. \& Yengoyan, L.S., 1981. Analysis of anthocyanins in Vitis vinifera wines and red colour versus aging by HPLC and spectrophotometry. Am. J. Enol. Vitic. 32, 257-261.

McGuire, R.G., 1992. Reporting of objective colour measurements. Hort. Sci. 27, 1254-1255

Robin, J.P., Abbal, P. \& Salmon, J.M., 1997. Fermeté et maturation du raisin. Définition et évolution de différents paramètres rhéologiques au cours de la maturation. J. Int. Sci. Vigne Vin 31, 127-138.

Ruiz Hernandez, M., 1996. Observations during ripening of red grapes of the Rioja region of Spain. Semana-Vitivinicola 51 (2629), 4577-4580.

Setser, C.S., 1984. Reflections and transmissions. J. Food Quality 6, 183-197.

Venencie, C., Uveira, M.N. \& Guiet, S., 1997. Maturité polyphénolique du raisin Mis en place d'une méthode d'analyse de routine. Rev. Fr. E. 167, 36-41.

Wang, D., Dowell, F.E. \& Lacey, R.E., 1999. Single wheat kernel colour classification using neural networks. Transactions of the ASAE 42, 233-240.

Wildenradt, H.L. \& Caputi, A., 1976. Collaborative study of the determination of colour in white wines. Journal of the Association of Official Analytical Chemists 59, 777-779.

Wrolstadt, R.E., 1976. Colour and pigment analyses in fruit products. Station Bulletin, Exp. St., Oregon State Univ. 624, 17. 